\title{
Selectivity of Second Language Attrition
}

\author{
Junyan Wei \\ School of Foreign Languages and Cultures, Nanjing Normal University, Nanjing, China
}

\begin{abstract}
The aim of this article is to provide an overview of second language attrition and its selective features. Second language attrition is reviewed from two different perspectives: from perspective of linguistic components as well as of language skills. Selectivity of second language attrition is analyzed in light of Markedness Theory, Retrieval Fail Hypothesis, Functional Load Theory and Regression Hypothesis. Following conclusions are obtained: 1) from the perspective of linguistic components, at intra-component level (within phonology, lexicon, morphology and syntax), second language attrition is selective: linguistic items, which are of high frequency, of high functional load and less marked, are maintained better during second language attrition; At inter-component level, generally, lexicon is more subjective to attrition than morphology and syntax, while phonology can be quite robust to attrition. 2) As for the perspective of language skills, productive skills are more subject to attrition than receptive skills.
\end{abstract}

Index Terms - second language attrition, selectivity, theoretical consideration

\section{INTRODUCTION}

Language attrition, known as the reverse process of language acquisition, is a relatively new branch of applied linguistics. Although there is a longstanding tradition of research on language loss or shift since the 1920s, the major impetus for language attrition research was given at a conference held at the University of Pennsylvania in 1980. Since then, a considerable body of research was carried out, and the research on second language attrition became one of its main fields. One of the most important issues in the field of second language attrition is "what is typically lost?" (Weltens, 1987, p.22). Evidences were provided showing that different linguistic components could be affected differently during language attrition. Researchers suggested that language attrition is selective. As more and more studies were carried out on this field, some relevant theories and hypotheses were proposed and confirmed.

To understand the nature of second langue attrition is of great importance. Since second language attrition is a reversal of second language acquisition, research results on the field of attrition can shed a light on second language teaching and learning. By figuring out what language features are more vulnerable to attrition, both second language learners and teachers can find methods to better maintain that language.

\section{LITERATURE REVIEW}

\section{A. Second Language Attrition}

Language attrition is the non-pathological loss of a first or second language or a portion of that language by individuals, taking place within one generation; it should be distinguished from language loss within a community (the latter is referred to as language shift or language death) (Köpke, 2004).

Depending on what is lost and the environment in which it is lost, language attrition can be divided into four areas, known as the "van Els taxonomy". These four areas are: first language (L1) loss in an L1 environment; L1 loss in a second language (L2) environment; L2 loss in an L1 environment; L2 loss in an L2 environment (Weltens, 1987). Among the four areas, L1 loss in an L1 environment can be observed in those aging people who are losing their first language; L1 loss in an L2 environment can be observed within the emigrants who lose their L1 in the new environment; L2 loss in an L1 environment can be observed among those who lose their second language learned at school, or those who once lived in a L2 environment and returned to their L1 environment; Finally, L2 loss in an L2 environment is usually observed within the aging immigrants who lose their L2. Both L2 loss in L1 environment and L2 loss in L2 environment can be considered as second language attrition.

Researches on second language attrition indicate that different linguistic features and language skills can be lost under different rates. Seliger (1991) pointed out second language attrition is selective and does not affect all aspects of language in the same way. Studies were carried out to find evidence for selectivity of second language attrition. Some researchers pointed that lexicon or syntax structures that are important to make distinctions in language use would be less subject to attrition (Anderson, 1982). Some researchers found that morphological elements, which are more frequently used, can be remained better during language attrition (Hansen and Chen, 2001). Some researchers compared the attrition rates of lexicon, morphology and syntax and pointed out that lexicon is more vulnerable to attrition than morphology and syntax, while phonology remains the most resistant (Tomiyama, 1999). Also, some argued even language skills could be affected at different rates by attrition--compared to listening and reading, speaking and writing would attrite more easily. However, some researcher pointed out that researches within perspective of selectivity in language attrition still lacks coherence (Köpke, 2004). Therefore, in this paper, we tried to divided selective features of 
language attrition into different categories and levels, and by applying some related theories and hypotheses, we tried to find answer to the question 'what is typically lost and why?'

\section{B. Related Theories and Hypotheses}

In the research of second language attrition, some theories and hypotheses are raised to explain why some structures are more subject to attrition. Among those hypotheses and theories, Markedness Theory, Functional Load Theory, Retrieval Fail Hypothesis and Regression Hypothesis are widely cited.

1.Markedness Theory

Markedness is a linguistic concept that developed out of the Prague School. A marked form is a non-basic or less natural form. An unmarked form is a basic, default form. Markedness originally developed from phonology and then has been extended to other areas as well, such as morphology, syntax and semantics. Grammatical forms that are more complex and have a narrow linguistic distribution are considered marked (Gürel, 2004). During language attrition, it is believed that linguistic elements that are marked would be more subject to attrition than those less marked forms (Anderson, 1982; Gürel, 2004; Hanson \& Chen, 2001).

2.Functional Load Theory

The term functional load refers to the extent and degree of contrast between certain linguistic units, usually phonemes, in making distinctions in a language (King, 1967). In the field of second language attrition, it is believed that when the loss of certain phonological, morphological or syntactical distinctions would result in frequent loss of information, these distinctions could be considered as of high functional load (Anderson, 1982). It is believed that linguistic feature with distinctions of high functional load would be maintained longer than others with low functional load.

3. Retrieval Fail Hypothesis

According to Retrieval Fail Hypothesis, forgetting is considered not as a loss of information, but as inaccessibility. "Forgetting is much like being unable to find something that we have misplaced somewhere. Forgetting occurs because the information we seek is temporarily inaccessible; if only we had the right retrieval cue, the information we seek could be successfully retrieved" (Loftus, 1976, P. 78). As for second language practice, it is common that one may recognize a certain word when he sees or hears it, but it would be harder if he needs to retrieve the word during production since there's not enough cues for him for remember (Ecke \& Peter, 2004). Gradually, language elements may be forgot due to the lack of retrieval cues.

4.Regression Hypothesis

Regression Hypothesis is one of the most widespread hypotheses explaining the nature of language attrition. The theory describes attrition as the mirror image of acquisition or learning (Weltens, 1987). In losing a language, one would always follow an order opposite to the stages of acquisition (Hanson, 2001). As a result, the last learned would be the first forgotten and the first learned would be the last forgotten (Freed, 1980). As for second language learners, this kind of opposite order of acquisition and attrition has been widely found in different perspectives and levels, from linguistic components to language skills (Cohen, 1986; Edwards, 1976; Hanson 1999; Hayashi, 1999; Tomiyama 1999; Weltens, 1987).

\section{Selectivity of SeCOnd LANGUage AtTrition}

Selectivity of second language attrition can be divided into two perspectives: selectivity of linguistic components and selectivity of language skills. Further more, selectivity of linguistic components can be analyzed at the intra-component level (within phonology, lexicon, morphology and syntax) and the inter-component level, and selectivity of language skills lies in the difference between receptive skills and productive skills.

\section{A. Selectivity of Linguistic Components}

Selectivity of linguistic components can be analyzed at two levels: the intra-component level and the inter-component level.

1. Selectivity at intra-component level

Traditionally, the intra-component level contains phonology, lexicon, morphology and syntax. Studies to date have found some evidence to confirm the selectivity of second language attrition at the intra-component level. Within the phonology, lexicon, morphology and syntax, some linguistic features would be more subject to attrition while some would be maintained better.

a. Phonology

In the field of phonological attrition, Studies by Dorian (1973) and Manessy (1977) showed that compared to native language, second language has less number and diversity of distinctive phonological features except where the phonological distinctions exist in both languages and where the distinctions in L2 carry a high functional load. According to the results of those studies, Anderson (1982) suggested in her hypothesis that 1) phonological distinctions existing both in the language learner's L1 and L2 would be more resistant to attrition; 2) phonological distinctions carrying a high functional load in L2 would be more resistant to attrition than those carrying a low functional load. 
Some proof can be found among Chinese EFL learners. When Chinese students begin to learn English as a second language, they always find consonant $[\theta]$ hard to pronounce. Taking the word 'thanks' for example, at the beginning, EFL learners in China often use the sound [s] to replace the sound $[\theta]$ since they do not have the pronunciation [ $\theta]$ in their mother tongue. According to Regression Hypothesis, what learned in the latter stages would be forgotten earlier. As a matter of fact, during second language attrition, the consonant [ $\theta$ ] is lost much more easily than consonants existing in Chinese. As for the second hypothesis, evidence can be found in the distinction between the consonant [n] and [n]. This distinction carries a low functional load. Some of the Chiniese EFL students prefer to pronounce [n] instead of $[\mathrm{y}]$ since it is easier to pronounce and seldom results in any misunderstanding in communication. For example, they may pronounce the word 'loving' as ['lı vı n]. Therefore, one can always find that among Chinese learners, during second language attrition, the sound $[\mathrm{y}]$ is lost earlier than others.

b. Lexicon

It is generally believed that lexical attrition is the more prevalent than phonology or syntax. Lots of studies have been carried out to find the rules of lexical attrition.

Manessy (1977) observed some non-native speakers of several African languages and found that they tend to use a small core of highly frequent and highly useful vocabulary. There were similar results in Blum and Levenston's (1978; 1980) studies that L2 learners tend to use the common, highly frequent, unmarked lexical items when they do not know certain less common, less frequent, highly marked items. Based on these studies, Anderson (1982) proposed a hypothesis that what lexicon the L2 has retained will be of common, highly frequent, unmarked lexical items; the gaps will be of less common, low frequency, and highly marked items. This hypothesis is based on Markedness Theory, and it received some proof from a study by Hansen and Chen (2001). In their study, they analyzed the attrition of numeral classifier systems of Japanese and Chinese and results suggested that the less marked classifier is less affected in attrition. Besides, their study also confirmed the Regression Hypothesis that classifiers learned in the earliest stages would be the last ones to forget.

There may be relationships between Markedness Theory and Regression Hypothesis. The reason why marked lexical items are easier to forget than less marked ones is possibly that the unmarked lexical items are usually more common in use and appear more frequently. Thus, unmarked items may be learned in the early stages. Since they are more common and more frequent in use, they may be more resistant to attrition.

Other researchers put their focuses on the attrition of receptive and productive lexicon. Gonzo and Saltarelli (1983) used two experimental techniques picture naming and word-picture matching in an experiment. The data showed that lexicon attrition was more commonly found in the former task than in the latter one. De Bot and Weltens (1995) provided an explanation for the result. In their explanation, the first task was a retrieval task in which the actual recall was required, but the second task was a recognition task in which only recognition was needed. And in the recognition task, the target item itself could be considered as a retrieval cue. According to the Retrieval Fail Hypothesis, the vocabulary with more retrieval cues may be more resistant to attrition. Thus, the receptive lexicon is less subject to attrition than the productive lexicon.

To sum up, in the field of lexicon attrition, lexical items, which are more frequently used and less marked, would be better retained during attrition and so do the receptive lexicon.

Proofs can be found among L2 learners. On one hand, words that are more frequently used are less vulnerable to attrition. Taking EFL students in China for example, when they are required to illustrate a certain category, fruits for example, the more frequently used words such as apple, banana, tomato and orange will jumped into their mind while those less common and less frequently used words such as lime, pineapple and grapefruit will take time for them to recall. And they may have learned words as durian or avocado, but as there's seldom any chance for them to use it in daily life. Gradually, they may forget those words. On the other hand, less marked words would be maintained better. Two words can be taken as an example, 'horse' and 'colt'. 'Horse' is always unmarked while 'colt', which means a little male horse, is always considered as marked. The EFL students may have known the word 'colt', but since in many situations the word 'horse' is enough for them to explain their ideas, 'colt' would be forgotten day on and day forth. For another example, in some languages, such as French, each word has its gender. In general, masculine words are unmarked while the feminine words are marked. 'le boeuf' is a masculine word, which means the cattle in general, and it is more often in use than the word ' la vache', meaning cows. As a result, Chinese students majoring in French forget the word ' la vache' much more easily than the word 'le boeuf'

c. Morphology

As for morphology, some early researches on second language acquisition suggested that learning of the grammatical morphemes is affected by both positive and negative transfer from the learner's native language (Hakuta \& Cancino, 1977; Larsen-Freeman, 1976). According to Larsen-Freeman's research, frequency of morphemes in native adults speech correlates with the acquisition orders among L2 learners. This finding suggests that morphemes that are most frequently used by native speakers would be learned first by the L2 learners.

In situations where languages are in contact, studies showed that the grammatical distinctions that are not shared by both languages are more subject to attrition. For example, evidence from a village where three languages are in contact showed that grammatical gender becomes reduced to semantic gender and agreement rule become simpler where the three languages do not have the same distinctions. (Gumperz \& Wilson, 1971) 
Some hypotheses were applied on morphological attrition. One hypothesis suggested that the morphological distinctions which appear with highest textual frequency by the native speakers would be maintained the longest by the L2 learners; and those appear with the lowest textual frequency would be the first to be lost. Also, based on regression hypothesis, those grammatical morphemes acquired in the early stages of learning would be retained the longest and those acquired in the late stages would be lost early. In addition, one hypothesis argued that the morphological categories marked both in one person's L1 and L2 would be better maintained in his L2.

To sum up, during morphology attrition, morphological items that are of higher textural frequency, of early acquisition, or that are marked in L2 as well as in L1 would be maintained better. Morphological items in the opposite situation would be more subject to attrition.

Among Chinese EFL students, proofs can be found in prefix 'un' and 'ir'. Prefix 'un' is of high frequency and is learned in the early stage during acquisition. Therefore, students often over generalize it when they need a word of opposite meaning. On the contrary, prefix 'ir' is of low frequency. As a result, prefix 'ir' is easily forgotten, and it is always taken place by prefix 'un'. Since English and Chinese have different morphological systems, there is seldom any interaction on morphological categories between these two languages. Those morphological rules not existing in Chinese are hard to learn and easy to forget. For Chinese EFL students, they always complain about inflections. Although inflections are learned during quite early stages, they are always forgotten in use, even for those learners reaching a comparatively high level of English.

d. Syntax

In the field of second language acquisition, some studies provided evidence for acquisition sequence of syntax. Schumann (1978) argued that in the early stages, learners would focus on the communicative function of syntax; therefore, the learners are negative to get more input. Because of this, they learned a restricted set of syntactic devices. In other words, the syntactic devices that have more communicative functions can be better retained. However, in latter stages of learning, learners would develop a wider repertoire of syntactic devices as they have sufficient need to expand the syntactic devices (Bickerton, 1977; Andersen, 1980).

In Gumperz and Wilson's (1971) research, they suggested that 'almost all the changes can be interpreted as reductions or generalizations that simplify surface structure in relation to underlying categories and relationships.' This can be interpreted as that the L2 learners always simplify the syntactic structures to the degree of the sufficient communication. This result indicates that the syntactic structures, which are simple, basic and useful in communication, are less subject to attrition.

Some hypotheses are proposed for syntactic attrition. One is that the syntactic structures that can reflect the underlying semantic and syntactic relations can be preserved better, and L2 speakers may even overuse them. This hypothesis indicates that during L2 attrition, these syntactic structures would be less subject to attrition. Another hypothesis is based on the function load theory, suggesting that where elimination of a syntactic construction of a given type would result in informational loss, that certain syntactic construction would be maintained in the use of the language. It is the same as the attrition of phonology - the grammatical devices with the higher functional load would be less vulnerable to $\mathrm{L} 2$ attrition.

In sum, syntactic structures, which are basic and frequently used, or are with high functional load would be maintained better during the process of syntactic attrition. It is common situation in Chinese EFL learners that they prefer simple sentences especially during oral communication. Structures as attributive clause, adverbial clause would sometimes be split into simple sentences. For those more complicated structures as inverted sentence or subjunctive mood, seldom any EFL Learners would use them during communication when attrition takes place, these kinds of structures would soon be forgotten.

2. Selectivity at inter-component level

In addition to selectivity of second language attrition at the intra-component level, researches also suggested that the selectivity exists at the inter-component level as well. Evidences showed that phonology, lexicon, morphology and syntax are affected to an unequal degree during second language attrition (Herdina \& Jessner, 2002).

Tomiyama (1999) carried out some researches on this field. She observed a Japanese boy called Ken, who left Japan for America at the age of 1 and retuned home at the age of 8. The study was on L2 attrition after the subject's returning to the L1 environment. The findings indicated the selectivity of second language attrition at the inter-component level. The result of the experiment on lexical attrition suggested that Ken's attrition in productive lexicon was evident. Compared to lexicon, data on morphological attrition suggested that attrition of morphology was less evident, only showing some possible signs of instability of irregular past and plural. And syntax seemed to be less affected by attrition with only a glimpse of indication in the relative clause structure. The receptive lexicon and the phonological skills remain unaffected by attrition. Tomiyama made a conclusion that for Ken, 'attrition first manifested as lexical retrieval difficulty. Some indications of attrition in morphology and syntax were present, but phonology and receptive lexicon remained quite robust throughout the course of the observation'.

On the contrary, De Bot and Weltens (1995) reported that after zero, two and four years of disuse of French a foreign language by the Dutch, learners displayed greater attrition in grammar than in phonology and lexicon. 
Yoshitomi (1992; 1999) provided an explanation for this difference. She suggested that more proficient students lose more vocabulary than grammar, while the pattern is reversed in less proficient students. This is probably because advanced students have a relatively stable knowledge of grammar and a larger amount of lexical knowledge.

The comperation between primary school students and college students can be an extreme example for the different patterns of L2 attrition. Based on personal observation as a teacher, primary school students forget about grammar much faster than vocabulary. On the contrary, college students, with higher proficiency in English, always complain about the difficulty in remembering vocabulary rather than learning grammar.

\section{B. Selectivity of Language Skills}

Basically, language skills can be divided in to two categories: receptive skills and productive skills. Listening and reading belong to receptive skills while speaking and writing belong to receptive skills. Hanson (1999) made a hypothesis that receptive skills precede productive skills in acquisition and the reverse is true in attrition. Results of some studies provided evidences to this hypothesis. Edwards (1976) studied second language retention in Canada and found an 8 percent gain in reading after 12 months, but a 13 per cent loss in speaking. Weltens (1987) observed the loss of French competence by speakers of Dutch and found that instead of attrition, listening proficiency and reading proficiency even increased over time. Tomiyama (1999), by studying second language attrition of a Japanese returnee, also concluded in her research that the subject's productive skill of lexicon was the first to be affected while his receptive skills was virtually unaffected.

There are some possible explanations. According to Retrieval Fail Hypothesis, if one had the right retrieval cue, the information that was temporarily inaccessible could be successfully retrieved. During listening and reading, retrieval cues could always be found in the text provided. Only recognition is needed. On the contrary, during speaking and writing, one has to recall the information he needs. Therefore, the productive skills are always more subject to attrition than receptive skills. Another explanation is based on Regression Hypothesis. Commonly, receptive skills are always learned earlier than the productive skills. Thus, during the process of attrition, the productive skills are always lost earlier than the receptive skills. For most L2 learners, it is common that when they come across a word they can recognize it, but when they need certain word in writing or speaking, they can hardly recall it. That is because receptive and productive language skills are affected by attrition under different rates.

\section{CONCLUSION}

This article attempted to provide an overview of researches on second language attrition and its selective features. Based on the analysis, following conclusions can be obtained: 1) from the perspective of linguistic components, second language attrition is selective. To be specific, at intra-component level (within phonology, lexicon, morphology and syntax), linguistic units that are of high frequency, of high functional load and less marked can be maintained better during second language attrition; Selectivity exists at inter-component level as well. Generally, lexicon is considered as more subject to attrition than morphology and syntax, while phonology can be quite robust. 2) As for the language skills, productive skills are more subject to attrition than the receptive skills.

However, this article mainly focused on linguistic aspects of second language attrition, extralinguistic aspects are not taken into consideration. Extralinguistic aspects such as onset proficiency of attrition, age at onset, length of exposure before attrition, length of attrition, attitude and motivation, gender also affect second language attrition (Hanson, 2011; Ni \& Yan, 2006; Schmid, 2006). Second language learners under different personal situations would be affected by second language attrition at different attrite speed. Further studies can combine linguistic aspects and extralinguistic aspects of language attrition together and provide more suggestions on acquiring and maintaining a second language. Besides, most of the studies in the field of second language attrition take Indo-European languages as both L1 and L2. Studies on different language families are needed in order to provide a broader view on second language attrition and its selective features. In addition, new research methods, especially on-line measures could be borrowed from other fields. By applying methods as eye tracking and ERPs, the nature of second language attrition would be studied in a more precise way, which might finally shed lights on the understanding of language processing in multi-lingual brains.

\section{REFERENCES}

[1] Andersen, R. (1980). Creolization as the acquisition of a second language as a first language. In Albert Valdman \& Arnold Highfield (Eds.), Theoretical orientations in creole studies. New York: Academic Press, 273-295.

[2] Andersen, R. (1982). Determining the linguistic attributes of language attrition. In R. Lambert and B. Freed (Eds.), The loss of language skills. Rowley, MA: Newbury House Publishers, 83-118.

[3] Bickerton, D. (1977). Pidginization and creolization: language acquisition and language universals. Pidgin and Creole Linguistics, 49, 69-72.

[4] Blum-Kulka, S., \& Levenston, E. (1978). Universals of lexical simplification. Language Learning, 28, 399-415.

[5] Blum-Kulka, S., \& Levenston, E. (1980). Lexical simplification in second-language acquisition. Studies in Second Language Acquisition, 2, 43-65.

[6] Cohen, A. D. (1986). Forgetting foreign language vocabulary. In Weltens, B., De Bot, K., \& van Els, T. (Eds.), Language Attrition in Progress. Dordrecht: Foris Publications Holland, 143-158.

[7] De Bot \& B. Weltens. (1995). Foreign language attrition. Annual Review of Applied Linguistics, 15,151-164. 
[8] Dorian, N. C. (1973). Grammatical change in a dying dialect. Language, 49(2), 413-438.

[9] Ecke, P. (2004). Language attrition and theories of forgetting: A cross-disciplinary review. International Journal of Bilingualism, 8(3), 321-354.

[10] Edwards, G. (1976). Second language retention in the Canadian public service. The Canadian Modern Language Review, 32 , 305-308.

[11] Freed, B. (1980). The Problem of Language Skill Loss. Paper presented at the Annual Meeting of the Modern Language Association, New York, December 1980.

[12] Gonzo, S. \& M. Saltarelli. (1983). Pidginization and linguistic change in emigrant languages. In R. Andersen (Ed.), Pidginization and creolization as language acquisition. Rowley, MA: Newbury House Publishers, 181-197.

[13] Gumperz, J. J., \& Wilson, R. (1971). Convergence and creolization. In Hymes, D.H. (Ed.), Pidginization and Creolization of Languages. New York: Syndics of the Cambridge University Press, 151-167.

[14] Gürel, A. (2004). Selectivity in L2-induced L1 attrition: a psycholinguistic account. Journal of Neurolinguistics, 17(1), 53-78.

[15] Hakuta, K., \& Cancino, H. (1977). Trends in second-language-acquisition research. Harvard Educational Review, 47(3), 294-316.

[16] Hansen, L. (Ed.). (1999). Second language attrition in Japanese contexts. New York: Oxford University Press.

[17] Hansen, L., \& Chen, Y. L. (2001). What counts in the acquisition and attrition of numeral classifiers? JALT Journal, 23(1), 83-100.

[18] Hansen, L. (2011). The acquisition, attrition, and relearning of mission vocabulary. In M.S. Schmid \& W. Lowie (Eds.), Modelling bilingualism: From structure to chaos. Amsterdam: John Benjamins, 115-134.

[19] Hayashi, B. (1999). Testing the regression hypothesis: The remains of the Japanese negation system. In Hanson, L. (Ed.), Second Language Attrition in Japanese Contexts. New York: Oxford University Press, 154-168.

[20] Herdina, P., \& Jessner, U. (2002). A Dynamic Model of Multilingualism: Changing the Psycholinguistic Perspective. Clevedon, UK: Multilingual Matters.

[21] King, R. D. (1967). Functional load and sound change. Language, 43(4), 831-852.

[22] Köpke, B. (2004). Neurolinguistic aspects of attrition. Journal of Neurolinguistics, 17, 3-30.

[23] Lambert, R. D., \& B. F. Freed. (1982). The loss of language skills. Rowley, MA: Newbury House Publishers.

[24] Larsen-Freeman, Diane. (1976). An explanation for morpheme acquisition order of second language learners. Language Learning, 26, 125-134.

[25] Loftus, G. and E. Loftus. (1976). Human Memory: The Processing of Information. Hillsdale, N.J.: Lawrence Erlbaum Associates.

[26] Manessy, G. (1977). Processes of pidginization in African languages. Pidgin and Creole Linguistics, 129, 154-161.

[27] Ni ChuanBing \& Yu RongJun. (2006). Analysis of the factors affecting foreign/second language attrition. Foreign Language Teaching and Research, 38, 51-55.

[28] Schimid, M.S. (2006). Second language attrition. In K. Brown (Ed.), The Encyclopedia of Language and Linguistics. Amsterdam: Elsevier, 74-81.

[29] Schumann, John H. (1978). The Pidginization process: A model for second language acquisition. Rowley, MA: Newbury House Publishers.

[30] Seliger, H. \& R. Vago. (1991). First language attrition. Cambridge: Cambridge University Press.

[31] Tomiyama, M. (1999). The first stage of second language attrition: a case study of a Japanese returnee. In L. Hansen (Ed.), Second language attrition in Japanese context. Oxford: Oxford University Press, 59-79.

[32] Weltens,B. (1987). The attrition of foreign-language skills: a literature review. Applied Linguistics 8, 22-36.

[33] Yoshitomi, A. (1999). On the loss of English as a second language by Japanese returnee children. In L. Hansen (Ed.), Second language attrition in Japanese context. Oxford: Oxford University Press, 80-111.

[34] Yoshitomi, A. (1992). Towards a model of language attrition: Neurobiological and psychological contributions. Issues in Applied Linguistics, 2, 293-381.

Junyan Wei was born in Nantong, China in 1985. She received her M.A. degree in Applied Linguistics from Nanjing Normal University, China in 2011.

She is currently a Ph.D. candidate in School of Foreign Languages and Cultures, Nanjing Normal University, Nanjing, China. Her research interests include Psycholinguistics, Second Language Acquisition and Second Language Attrition. 